\title{
Penyelesaian Numerik Persamaan Advection Dengan Radial Point Interpolation Method dan Integrasi Waktu Dengan Discontinuous Galerkin Method
}

\author{
Kresno Wikan Sadono \\ Departemen Teknik Sipil, Fakultas Teknik, Universitas Diponegoro, \\ Jl. Prof. Soedarto, SH, Kampus Undip Tembalang, Semarang, Indonesia 50275
}

\begin{abstract}
Abstrak
Persamaan differensial banyak digunakan untuk menggambarkan berbagai fenomena dalam bidang sains dan rekayasa. Berbagai masalah komplek dalam kehidupan sehari-hari dapat dimodelkan dengan persamaan differensial dan diselesaikan dengan metode numerik. Salah satu metode numerik, yaitu metode meshfree atau meshless berkembang akhir-akhir ini, tanpa proses pembuatan elemen pada domain. Penelitian ini menggabungkan metode meshless yaitu radial basis point interpolation method (RPIM) dengan integrasi waktu discontinuous Galerkin method (DGM), metode ini disebut RPIM-DGM. Metode RPIM-DGM diaplikasikan pada advection equation pada satu dimensi. RPIM menggunakan basis function multiquadratic function (MQ) dan integrasi waktu diturunkan untuk linear-DGM maupun quadratic-DGM. Hasil simulasi menunjukkan, metode ini mendekati hasil analitis dengan baik. Hasil simulasi numerik dengan RPIM DGM menunjukkan semakin banyak node dan semakin kecil time increment menunjukkan hasil numerik semakin akurat. Hasil lain menunjukkan, integrasi numerik dengan quadratic-DGM untuk suatu time increment dan jumlah node tertentu semakin meningkatkan akurasi dibandingkan dengan linear-DGM.
\end{abstract}

Kata kunci: persamaan differensial; meshfree; meshles; radial basis point interpolation method; discontinuous Galerkin method; advection equation

\begin{abstract}
[Title: Numerical solution of advection equation with radial basis interpolation method and discontinuous Galerkin method for time integration] Differential equation is widely used to describe a variety of phenomena in science and engineering. A variety of complex issues in everyday life can be modeled with differential equations and solved by numerical method. One of the numerical methods, the method meshfree or meshless developing lately, without making use of the elements in the domain. The research combines methods meshless, i.e. radial basis point interpolation method with discontinuous Galerkin method as time integration method. This method is called RPIM-DGM. The RPIM-DGM applied to one dimension advection equation. The RPIM using basis function multiquadratic function and time integration is derived for linear-DGM and quadratic-DGM. The simulation result shows that this numerical method, close to the results exact well. The results of numerical simulations with RPIM-DGM show, the more nodes and the smaller the time increment, the more accurate the numerical results. Other results showed, integration with quadratic-DGM for a time increment, and a certain number of nodes, further improving accuracy, compared with the linear-DGM.
\end{abstract}

Keywords: differential equation; meshfree; meshless; radial point interpolation method; discontinuous Galerkin method; advection equation

\section{Pendahuluan}

Fenomena pada bidang sains dan rekayasa dapat dimodelkan dengan persamaan differensial atau differential equation (DE). Untuk beberapa kasus yang sangat sederhana tersedia solusi analitik atau eksak (exact) untuk DE tersebut. Namun pada masalah real dalam kehidupan sehari-hari yang sangat rumit solusi analitis tidak tersedia. Sehingga metode

E-mail: kresnowikan@gmail.com numerik merupakan salah satu metode yang digunakan untuk menyelesaikan DE yang kompleks.

Pada metode numerik tertentu, domain pada suatu masalah dapat dibagi menjadi sub-domain yang disebut element atau cell. Penyelesaian numerik dengan metode ini disebut mesh based method, dimana finite element method (FEM), discontinuous Galerkin method (DGM) dan finite volume method (FVM) termasuk didalamnya.

Akhir-akhir ini berkembang beberapa metode numerik yang tidak menggunakan element atau cell, hanya menyebar node pada domain dan boundary, 
metode tersebut disebut meshfree atau meshless. Metode meshless memiliki keuntungan karena mesh dari domain tidak dilakukan sehingga simulasi lebih sederhana (Belytschko dkk., 1994; Liu dkk., 1995; Dolbow dan Belytschko, 1998). Metode smothed particle hydrodynamics (SPH), element free Galerkin (EFG), radial basis function (RBF) dan radial point interpolation method (RPIM) termasuk metode meshfree atau meshless tersebut.

Metode numerik misalnya, finite difference method (FDM), FEM, DGM, FMV, SPH, EFG, RBF dan RPIM dapat dikombinasikan untuk penyelesaian numerik pada domain ruang dan waktu, misalnya RBF dengan integrasi waktu Runge-Kutta (FDM) (Sarra \& Kansa, 2010) dan SPH dengan integrasi waktu (time integration) leap frog (FDM) (Monaghan, 1992). Selain itu DE dapat diselesaikan secara serentak pada domain ruang dan waktu sekaligus dengan satu metode, misalnya FEM untuk penyelesaian domain ruang dan waktu yaitu, space time finite element method (Baptisa, 2011).

Penelitian yang telah ada menggunakan RPIM untuk menyelesaikan berbagai masalah pada domain ruang tanpa melibatkan integrasi waktu, (Liu, 2003). Penelitian ini menggembangkan metode RPIM yang telah ada dengan menambahkan integrasi waktu dengan DGM. Penambahan integrasi waktu dengan DGM memungkinkan dilakukan simulasi DE yang melibatkan domain waktu maupun masalah yang berkaitan dengan waktu.

Penelitian ini bertujuan menurunkan RPIM untuk penyelesaian domain ruang dan integrasi waktu dengan DGM, skema tersebut dinamakan RPIMDGM. Perilaku numerik RPIM-DGM diselidiki dengan mengaplikasikan pada advection equation pada satu dimensi.

\section{Metode}

Persamaan diferensial parsial (partial differential equation, PDE) tipe advection untuk satu dimensi pada sumbu $x$, dinyatakan pada Persamaan 1 , untuk $x_{l} \leq x \leq x_{r}$ dan $t>0$.

$$
\frac{\partial u(x, t)}{\partial t}-\frac{\partial u(x, t)}{\partial x}=0
$$

Dimana $u(x, t)$ adalah unknown, $x$ adalah sumbu ruang, $t$ adalah waktu, $x_{l}$ adalah batas kiri (left boundary) dan $x_{r}$ adalah batas kanan (right boundary). Boundary condition (BC) dan initial condition (IC) dinyatakan pada Persamaan 2 (Sara \& Kansa, 2010).

$$
u\left(x_{r}, t\right)=0 ; u(x, 0)=e^{-c\left(x-x_{0}\right)^{2}}
$$

Solusi analitik atau exact solution dari persamaan advection dinyatakan dalam Persamaan 3, (Sara \& Kansa, 2010).

$$
u(x, t)=e^{-c\left(x-x_{0}+t\right)^{2}}
$$

Penggabungan skema RPIM dengan DGM dilakukan dengan menggunakan partial discretization (Zienkiewicz \& Morgan, 1982).

Jika suatu fungsi $u(\mathbf{x})$ didefinisikan pada suatu domain $\Omega$ yang direpresentasikan dengan $n$ buah node yang tersebar pada support domain. Point interpolation method (PIM) melakukan interpolasi $u(\mathbf{x})$ dengan menggunakan nilai pada node pada support domain dengan pusat geometri $\mathbf{x}_{\mathrm{Q}}$ (Liu, 2003).

Untuk interpolasi suatu unknown $u(\mathbf{x})$ pada suatu domain $\Omega$ dengan $n$ buah node yang tersebar pada support domain dinyatakan dengan Persamaan 4.

$$
=\sum_{i=1}^{n} R_{i}(\mathbf{x}) a_{i}\left(\mathbf{x}_{\mathrm{Q}}\right)=\mathbf{R}^{\mathrm{T}}(\mathbf{x}) \mathbf{a}\left(\mathbf{x}_{\mathrm{Q}}\right)
$$$$
u_{h}\left(\mathbf{x}, \mathbf{x}_{\mathbf{Q}}\right)
$$

Nilai $u_{h}$ adalah unknown yang dicari, $R_{i}(\mathbf{x})$ adalah radial basis function, $a_{i}\left(\mathbf{x}_{\mathrm{Q}}\right)$ adalah konstanta. Untuk kasus 2 dimensi nilai $\mathbf{x}=\left[\begin{array}{ll}x & y\end{array}\right]$. Nilai basis function $\mathbf{R}(\mathbf{x})$ dinyatakan dalam Persamaan 5.

$$
\mathbf{R}^{\mathrm{T}}(\mathbf{x})=\left[\begin{array}{llll}
R_{1}(\mathbf{x}) & R_{2}(\mathbf{x}) & \ldots & R_{n}(\mathbf{x})
\end{array}\right]
$$

Nilai dari basis function menggunakan tipe multiquadratic (MQ), (Sara \& Kansa, 2010) dinyatakan pada Persamaan 6

$$
R_{i}(x, y)=\sqrt{1+\varepsilon^{2} r_{i}^{2}}
$$

Dengan $\varepsilon$ adalah shape parameter dan $r_{i}$ adalah jarak antara node dinyatakan pada Persamaan 7.

$$
r_{i}=\sqrt{\left(x-x_{i}\right)^{2}-\left(y-y_{i}\right)^{2}}
$$

Dengan membuat $u(\mathbf{x})$ memotong pada tiap node yang tersebar pada support domain dengan pusat geometri $\mathbf{x}_{\mathrm{Q}}$ maka moment matrix $\mathrm{RBF}$ dinyatakan dalam Persamaan 8 .

$$
\mathbf{R}_{\mathrm{Q}}=\left[\begin{array}{cccc}
R_{1}\left(r_{1}\right) & R_{2}\left(r_{1}\right) & \ldots & R_{n}\left(r_{1}\right) \\
R_{1}\left(r_{2}\right) & R_{2}\left(r_{2}\right) & \ldots & R_{n}\left(r_{2}\right) \\
\vdots & \vdots & \ddots & \vdots \\
R_{1}\left(r_{n}\right) & R_{2}\left(r_{n}\right) & \ldots & R_{n}\left(r_{n}\right)
\end{array}\right]
$$

Interpolasi untuk $k$ node dinyatakan pada Persamaan 9.

$$
u_{k}=u\left(x_{k}, y_{k}\right)=\sum_{i=1}^{n} R_{i}\left(x_{k}, y_{k}\right) a_{i}
$$

Persamaan 9 dapat dinyatakan dalam bentuk matrik sesuai Persamaan 10.

$$
\mathbf{U}_{\mathrm{s}}=\mathbf{R}_{\mathrm{Q}} \mathbf{a}
$$


Dengan inversi Persamaan 10 untuk a dan mensubstitusikan Persamaan 10 ke Persamaan 4 menghasilkan Persamaan 11

$u_{h}(\mathbf{x})=\mathbf{R}^{\mathrm{T}}(\mathbf{x}) \mathbf{R}_{\mathrm{Q}}^{-1} \mathbf{U}_{\mathrm{s}}=\boldsymbol{\Phi}(\mathbf{x}) \mathbf{U}_{\mathrm{s}}=\Phi_{i}(\mathbf{x}) u_{i}$

dimana

$$
\boldsymbol{\Phi}(\mathbf{x})=\left[\begin{array}{llll}
R_{1} & R_{2} & \cdots & R_{n}
\end{array}\right] \mathbf{R}_{\mathbf{Q}}^{-1}
$$

Sehingga nilai unknown $u(\mathbf{x})$ dapat didekati dengan menggunakan Persamaan 13.

$$
u_{h}(\mathbf{x})=\boldsymbol{\Phi}(\mathbf{x}) \mathbf{U}_{\mathbf{s}}
$$

Untuk kasus satu dimensi, Persamaan 13 dapat dinyatakan pada Persamaan 14. Persamaan 14 memiliki independent variable berupa skalar $x$ sedangkan Persamaan 13 independent variable berupa vektor $\mathbf{x}$.

$$
u_{h}(x)=\sum_{I=1}^{n} \Phi_{I}(x) u_{I}=\boldsymbol{\Phi}(x) \mathbf{U}_{\mathrm{s}}
$$

Dengan substitusi unknown pada advection equation Persamaan 1 dan mengalikan dengan test function $\Phi_{j}$ dan integrasi pada background mesh $\Omega_{p}$ menghasilkan Persamaan 15, untuk $\Phi_{j}=\Phi_{1}, \Phi_{2}, \ldots, \Phi_{n}$.

$$
\sum_{p=1}^{L} \int_{\Omega_{p}}\left(\Phi_{j} \frac{\partial u_{h}}{\partial t}-\Phi_{j} \frac{\partial u_{h}}{\partial x}\right) \mathrm{d} x=0
$$

Dengan substitusi Persamaan 14 pada Persamaan 15 menghasilkan Persamaan 16.

$\sum_{p=1}^{L} \int_{\Omega_{p}}\left(\Phi_{j} \frac{\partial}{\partial t}\left(\sum_{i=1}^{n} \Phi_{i} u_{i}\right)-\Phi_{j} \frac{\partial}{\partial x}\left(\sum_{i=1}^{n} \Phi_{i} u_{i}\right)\right) \mathrm{d} x=0$

Persamaan 16 dapat ditulis dalam bentuk matrik pada Persamaan 17. Persamaan 17 merupakan sistem persamaan differensial biasa atau system ordinary differential equation (system ODE) yang diselesaikan dengan integrasi waktu.

$$
\mathbf{C} \frac{\partial \mathbf{u}}{\partial t}-\mathbf{K u}=\mathbf{0}
$$

dimana

$$
\mathbf{C}=\int_{\Omega_{p}}\left[\begin{array}{c}
\Phi_{1} \\
\Phi_{2} \\
\vdots \\
\Phi_{n}
\end{array}\right]\left[\begin{array}{llll}
\Phi_{1} & \Phi_{2} & \cdots & \Phi_{n}
\end{array}\right] \mathrm{d} x
$$

$$
\begin{gathered}
\mathbf{K}=\int_{\Omega_{p}}\left[\begin{array}{c}
\Phi_{1} \\
\Phi_{2} \\
\vdots \\
\Phi_{n}
\end{array}\right]\left[\begin{array}{llll}
\frac{\partial \Phi_{1}}{\partial x} & \frac{\partial \Phi_{2}}{\partial x} & \cdots & \frac{\partial \Phi_{n}}{\partial x}
\end{array}\right] \mathrm{d} x \\
\frac{\partial \mathbf{u}}{\partial x}=\left[\begin{array}{llll}
\frac{\partial u_{1}}{\partial t} & \frac{\partial u_{2}}{\partial t} & \cdots & \frac{\partial u_{n}}{\partial t}
\end{array}\right]^{T} \\
\mathbf{u}=\left[\begin{array}{llll}
u_{1} & u_{2} & \cdots & u_{n}
\end{array}\right]^{T}
\end{gathered}
$$

\section{Integrasi Waktu dengan DGM}

Dengan pendekatan RPIM pada domain ruang pada persamaan advection pada Persamaan 1, terbentuk system ODE pada Persamaan 17. Persamaan ini selanjutnya diselesaikan dengan integrasi waktu, dengan DGM.

Skema DGM memiliki prosedur sama dengan FEM. System ODE yang dihasilkan pada Persamaan 17 dikalikan dengan test function $\psi_{l}$ dan diintegrasikan pada sub-domain waktu. Integrasi dilakukan pada elemen atau sub-domain waktu $\left[t_{k}, t_{k+1}\right](\mathrm{Li}, 2005)$ (Hesthaven \& Warburton, 2006).

$$
\int_{t_{k}}^{t_{k+1}}\left(\mathbf{C} \frac{\mathrm{d} \mathbf{u}}{\mathrm{d} t}-\mathbf{K u}\right) \psi_{l}(t) \mathrm{d} t=0
$$

Nilai $\mathbf{u}(t)$ didekati $\widehat{\mathbf{u}}(t(\xi))$ dengan independent variable waktu $t$ ditransformasi pada natural coordinate $\xi$, untuk linear element DGM atau linearDGM dinyatakan pada Persamaan 23.

$$
\widehat{\mathbf{u}}(t(\xi))=\mathbf{u}_{k}^{+} \psi_{1}^{1}(\xi)+\mathbf{u}_{k+1}^{-} \psi_{2}^{1}(\xi)
$$

Untuk linear element, shape function $\psi_{1}^{1}$ dan $\psi_{2}^{1}$ dinyatakan pada Persamaan 24a dan 24b.

$$
\begin{aligned}
& \psi_{1}^{1}(\xi)=\frac{1}{2}(1-\xi(t)) \\
& \psi_{2}^{1}(\xi)=\frac{1}{2}(1+\xi(t))
\end{aligned}
$$

Transformasi koordinat waktu $t$ ke natural coordinate ( $)$, dinyatakan pada Persamaan 25.

$$
t(\xi)=\frac{1}{2}\left(t_{n}+t_{n+1}\right)+\frac{1}{2} \xi\left(t_{n+1}-t_{n}\right)
$$

Dimana turunan Persamaan 25 dinyatakan pada Persamaan 26.

$$
\mathrm{d} t=\frac{\Delta t}{2} \mathrm{~d} \xi=\frac{\left(t_{k+1}-t_{k}\right)}{2} \mathrm{~d} \xi
$$

Dengan integration by parts dua kali, dan mensubstitusikan Persamaan 23, 24 dan 26 ke Persamaan 22 untuk $\psi_{l}=\psi_{1}^{1}$ maka menghasilkan Persamaan 27. 


$$
\begin{aligned}
& \mathbf{C u}^{+}\left(t_{k}\right) \psi_{1}^{1}\left(t_{k}\right)-\mathbf{C u}^{-}\left(t_{k}\right) \psi_{1}^{1}\left(t_{k}\right) \\
& +\int_{-1}^{+1}\left(\psi_{1}^{1} \mathbf{C} \frac{\mathrm{d}}{\mathrm{d} t}\left(\mathbf{u}_{k}^{+} \psi_{1}^{1}+\mathbf{u}_{k+1}^{-} \psi_{2}^{1}\right)\right. \\
& \left.-\mathbf{K}\left(\mathbf{u}_{k}^{+} \psi_{1}^{1}+\mathbf{u}_{k+1}^{-} \psi_{2}^{1}\right) \psi_{1}^{1}\right) \frac{\Delta t}{2} \mathrm{~d} \xi=0
\end{aligned}
$$

Dengan menyelesaikan Persamaan 27 maka menghasilkan Persamaan 28.

$$
\begin{aligned}
& \frac{1}{2} \mathbf{C} \mathbf{u}_{k}^{+}+\frac{1}{2} \mathbf{C u}_{k+1}^{+}-\frac{1}{3} \Delta t \mathbf{K u}_{k}^{+}-\frac{1}{6} \Delta t \mathbf{K u}_{k+1}^{-} \\
& =\mathbf{C u}_{k}^{-}
\end{aligned}
$$

Dengan cara yang sama dengan diatas, untuk $\psi_{l}=\psi_{2}^{1}$ menghasilkan Persamaan 29.

$$
\begin{aligned}
& \mathbf{C u}^{+}\left(t_{k}\right) \psi_{2}^{1}\left(t_{k}\right)-\mathbf{C u}^{-}\left(t_{k}\right) \psi_{2}^{1}\left(t_{k}\right) \\
& +\int_{-1}^{+1}\left(\psi_{2}^{1} \mathbf{C} \frac{\mathrm{d}}{\mathrm{d} t}\left(\mathbf{u}_{k}^{+} \psi_{1}^{1}+\mathbf{u}_{k+1}^{-} \psi_{2}^{1}\right)\right. \\
& \left.-\mathbf{K}\left(\mathbf{u}_{k}^{+} \psi_{1}^{1}+\mathbf{u}_{k+1}^{-} \psi_{2}^{1}\right) \psi_{2}^{1}\right) \frac{\Delta t}{2} \mathrm{~d} \xi=0
\end{aligned}
$$

Penyelesaian Persamaan 29, menghasilkan Persamaan 30.

$$
\begin{aligned}
& -\frac{1}{2} \mathbf{C u}_{k}^{+}+\frac{1}{2} \mathbf{C u}_{k+1}^{-}-\frac{1}{6} \Delta t \mathbf{K u}_{k}^{+}-\frac{1}{3} \Delta t \mathbf{K u}_{k+1}^{-} \\
& =0
\end{aligned}
$$

Dengan menggabungkan Persamaan 28 dan Persamaan 30, menghasilkan Persamaan 31. Persamaan 31 merupakan persamaan numerik untuk linear-DGM.

$$
=\left[\begin{array}{c}
\mathrm{Cu}_{k}^{-} \\
\\
0
\end{array}\right]
$$

Untuk integrasi waktu dengan quadratic-DGM, unknown $\widehat{\mathbf{u}}(t(\xi))$ dinyatakan dengan Persamaan 32.

$$
\begin{aligned}
& \widehat{\mathbf{u}}(t(\xi)) \\
& =\mathbf{u}_{k}^{+} \psi_{1}^{2}(\xi)+\mathbf{u}_{k+\frac{1}{2}} \psi_{2}^{2}(\xi) \\
& +\mathbf{u}_{k+1}^{-} \psi_{3}^{2}(\xi)
\end{aligned}
$$

Dimana shape parameter untuk quadratic-DGM dinyatakan pada Persamaan 33a, 33b dan 33c

$$
\begin{aligned}
\psi_{1}^{2}(\xi) & =\frac{1}{2}\left(\xi^{2}(t)-\xi(t)\right) \\
\psi_{3}^{2}(\xi) & =\frac{1}{2}\left(\xi^{2}(t)+\xi(t)\right) \\
\psi_{2}^{2}(\xi) & =-\xi^{2}(t)+1
\end{aligned}
$$

Dengan memasukkan Persamaan 32 dan Persamaan 33a, 33b dan 33c pada Persamaan 22, dan untuk $\psi_{l}=\psi_{1}^{2}$ menghasilkan 34 .

$$
\begin{aligned}
& \mathbf{C u}^{+}\left(t_{k}\right) \psi_{1}^{2}\left(t_{k}\right)-\mathbf{C u}^{-}\left(t_{k}\right) \psi_{1}^{2}\left(t_{k}\right) \\
& +\int_{-1}^{+1}\left(\psi_{1}^{2} \mathbf{C} \frac{\mathrm{d}}{\mathrm{d} t}\left(\mathbf{u}_{k}^{+} \psi_{1}^{2}+\mathbf{u}_{k+\frac{1}{2}} \psi_{2}^{2}+\mathbf{u}_{k+1}^{-} \psi_{3}^{2}\right)\right. \\
& \left.-\mathbf{K}\left(\mathbf{u}_{k}^{+} \psi_{1}^{2}+\mathbf{u}_{k+\frac{1}{2}} \psi_{2}^{2}+\mathbf{u}_{k+1}^{-} \psi_{3}^{2}\right) \psi_{1}^{2}\right) \frac{\Delta t}{2} \mathrm{~d} \xi \\
& =0
\end{aligned}
$$

Dengan menyelesaikan Persamaan 34 maka menghasilkan Persamaan 35.

$$
\begin{aligned}
& \frac{1}{2} \mathbf{C} \mathbf{u}_{k}^{+}-\frac{2}{15} \Delta t \mathbf{K u}_{k}^{+}+\frac{2}{3} \mathbf{C u}_{k+\frac{1}{2}}-\frac{2}{15} \Delta t \mathbf{K u}_{k+\frac{1}{2}} \\
& -\frac{1}{6} \mathbf{C u}_{k+1}^{-}+\frac{1}{30} \Delta t \mathbf{K u}_{k+1}^{-}=\mathbf{C u}_{k}^{-}
\end{aligned}
$$

Dengan cara yang sama, untuk $\psi_{l}=\psi_{2}^{2}$ menghasilkan Persamaan 36.

$$
\begin{aligned}
& -\frac{2}{3} \mathbf{C} \mathbf{u}_{k}^{+}-\frac{1}{15} \Delta t \mathbf{K} \mathbf{u}_{k}^{+}-\frac{8}{15} \Delta t \mathbf{K} \mathbf{u}_{k+\frac{1}{2}}+\frac{2}{3} \mathbf{C u}_{k+1}^{-} \\
& -\frac{1}{15} \Delta t \mathbf{K} \mathbf{u}_{k+1}^{-}=0
\end{aligned}
$$

Untuk $\psi_{l}=\psi_{3}^{2}$ menghasilkan Persamaan 37.

$$
\begin{aligned}
& \frac{1}{6} \mathbf{C u}_{k}^{+}-\frac{1}{30} \Delta t \mathbf{K u}_{k}^{+}-\frac{2}{3} \mathbf{C u}_{k+\frac{1}{2}}-\frac{1}{15} \Delta t \mathbf{K u}_{k+\frac{1}{2}} \\
& +\frac{1}{2} \mathbf{C u}_{k+1}^{-}-\frac{2}{15} \Delta t \mathbf{K u}_{k+1}^{-}=0
\end{aligned}
$$

Persamaan-persamaan 35, 36 dan 37 dapat dinyatakan dalam bentuk matrik pada Persamaan 38.

$$
\begin{aligned}
& {\left[\begin{array}{ccc}
\frac{1}{2} \mathbf{C}-\frac{2}{15} \Delta t \mathbf{K} & \frac{2}{3} \mathbf{C}-\frac{2}{15} \Delta t \mathbf{K} & -\frac{1}{6} \mathbf{C}+\frac{1}{30} \Delta t \mathbf{K} \\
-\frac{2}{3} \mathbf{C}-\frac{1}{15} \Delta t \mathbf{K} & -\frac{8}{15} \Delta t \mathbf{K} & \frac{2}{3} \mathbf{C}-\frac{1}{15} \Delta t \mathbf{K} \\
\frac{1}{6} \mathbf{C}-\frac{1}{30} \Delta t \mathbf{K} & -\frac{2}{3} \mathbf{C}-\frac{1}{15} \Delta t \mathbf{K} & \frac{1}{2} \mathbf{C}-\frac{2}{15} \Delta t
\end{array}\right]\left[\begin{array}{c}
\mathbf{u}_{k}^{+} \\
\mathbf{u}_{k+\frac{1}{2}} \\
\mathbf{u}_{k+1}^{-}
\end{array}\right]} \\
& =\left[\begin{array}{c}
\mathbf{C} \mathbf{u}_{k}^{-} \\
\mathbf{0} \\
\mathbf{0}
\end{array}\right]
\end{aligned}
$$

Persamaan 38 merupakan persamaan numerik untuk quadratic-DGM.

\section{Pengujian Numerik}

Berikut ini diaplikasikan RPIM DGM untuk advection equation. Pengujian numerik dilakukan dimana $x$ sebagai domain ruang dengan $x_{l} \leq x \leq$ $x_{r}$ dengan $x_{l}=0.0$ dan $x_{r}=2.0$. Node disebar merata pada domain ruang dengan jarak sama, node yang digunakan 11 buah node $(\Delta x=0.2), 21$ node 
$(\Delta x=0.1), 201$ node $(\Delta x=0.01)$ dan 401 node $(\Delta x=0.005)$.

Integrasi waktu dilakukan dengan linear dan quadratic DGM, dengan initial time $t=0$ dan final time $t=1$, dengan time increment, $\Delta t$ sebesar 0.5, 0.1 dan 0.01. Nilai $d_{\max }=2.0$ dan $\varepsilon$ adalah shape parameter diambil 0.5 . Hasil simulasi numerik RPIMDGM dibandingkan dengan solusi exact pada Persamaan 3, dan error dibandingkan untuk beragam jumlah node, variasi time increment dan tipe integrasi waktu linear-DGM atau quadratic-DGM. Error dinyatakan error $=u_{\text {exact }}-u_{\mathrm{EFG}-\mathrm{RPIM}}$. Error dapat dinyatakan $\log _{10} \|$ error $\|_{2}$ atau $\log _{10} \| u_{\text {exact }}-$ $u_{\text {EFG-DGM }} \|_{2}$ dapat disajikan dalam grafis atau numeris.

Hasil simulasi untuk 21 node $(\Delta x=0.1)$ dan $\Delta t=0.1$ untuk RPIM-DGM terhadap hasil exact ditampilkan pada Gambar 1 dan 2, dengan RPIM linear-DGM pada Gambar 1 dan RPIM quadraticDGM pada Gambar 2. Hasil simulasi menunjukkan RPIM-linear DGM dapat mendekati hasil exact dengan baik. Hasil RPIM-quadratic DGM ditampilkan pada Gambar 2 tidak banyak berbeda dengan RPIM-linear DGM. Hasil simulasi untuk 201 node $(\Delta x=0.01)$ dengan $\Delta t=0.1$, untuk RPIM linear-DGM ditampilkan pada Gambar 3 sedangkan untuk RPIM quadratic-DGM pada Gambar 4, dimana garis putus-putus (RPIM DGM) berimpit dengan hasil exact.

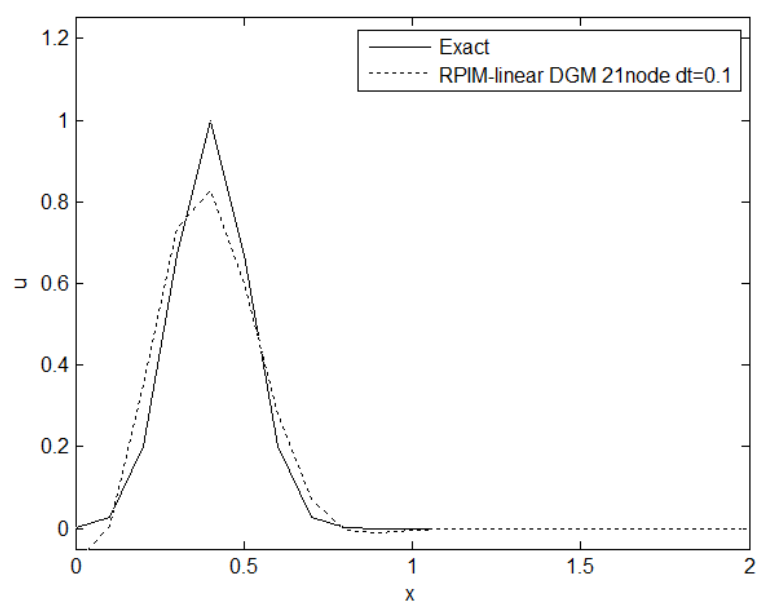

Gambar 1. Hasil RPIM DGM terhadap exact dengan 21 node $(\Delta x=0.1)$ dan $\Delta t=0.1$, pada $t=1.0$ dengan linear-DGM.

Simulasi time history error dengan berbagai variasi jumlah node dan time increment $(\Delta t)$ pada RPIM linear-DGM ditampilkan pada Gambar 5, 6, 7 dan 8. Time history error meningkat sejalan waktu, kecuali untuk jumlah node 11 untuk $\Delta t=0.5$. Hal ini menunjukkan bahwa solusi mengalami konvergensi atau convergence. Secara umum, pada Gambar 5, 6, 7 dan 8, menunjukkan semakin banyak node untuk simulasi (h-refinement) maka error semakin rendah dan semakin kecil time increment maka error semakin rendah, kecuali jumlah node 11 dan 21 . Untuk jumlah node 11 dan 21 terdapat osilasi time history error. Osilasi time history error tidak ditemui untuk jumlah node 201 dan 401. Nilai max $\log _{10} \|$ error $\|_{2}$ dengan RPIM linear-DGM ditampilkan pada Tabel 1.

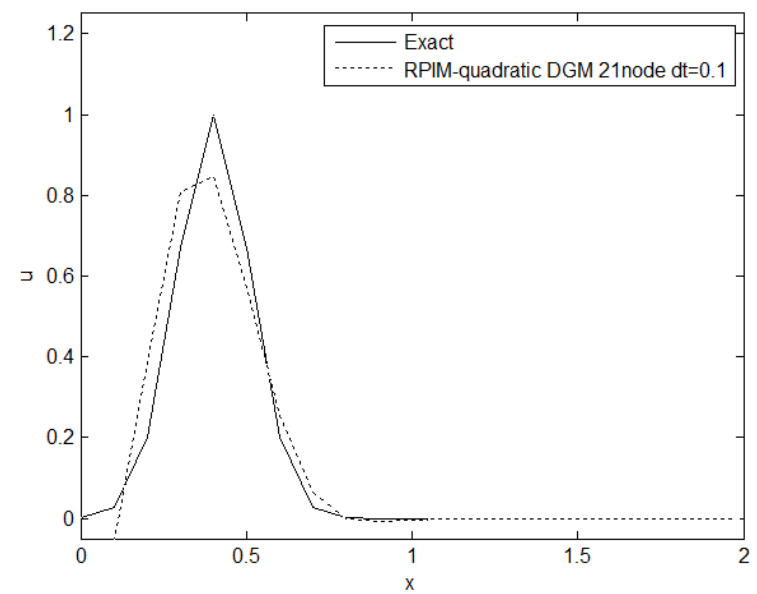

Gambar 2. Hasil RPIM DGM terhadap exact dengan 21 node $(\Delta x=0.1)$ dan $\Delta t=0.1$, pada $t=1.0$ dengan quadratic-DGM.

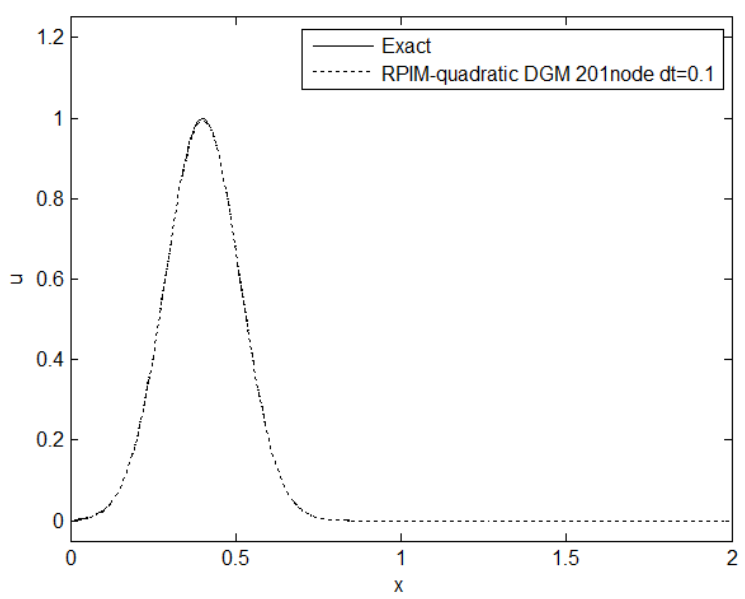

Gambar 3. Hasil RPIM quadratic-DGM terhadap exact dengan 201 node $(\Delta x=0.1)$ untuk $\Delta t=0.1$

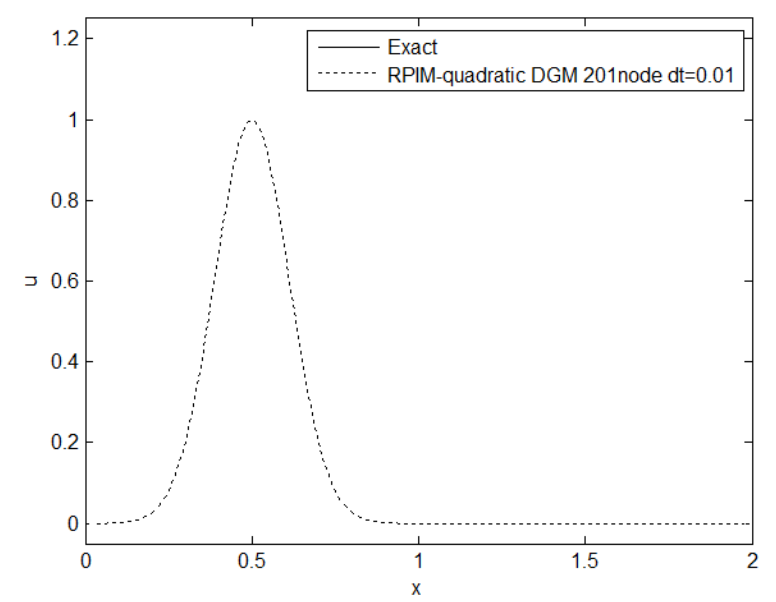

Gambar 4. Hasil RPIM quadratic-DGM terhadap exact dengan 201 node $(\Delta x=0.1)$ untuk $\Delta t=0.01$ 
Teknik, 37 (2), 2016, 69

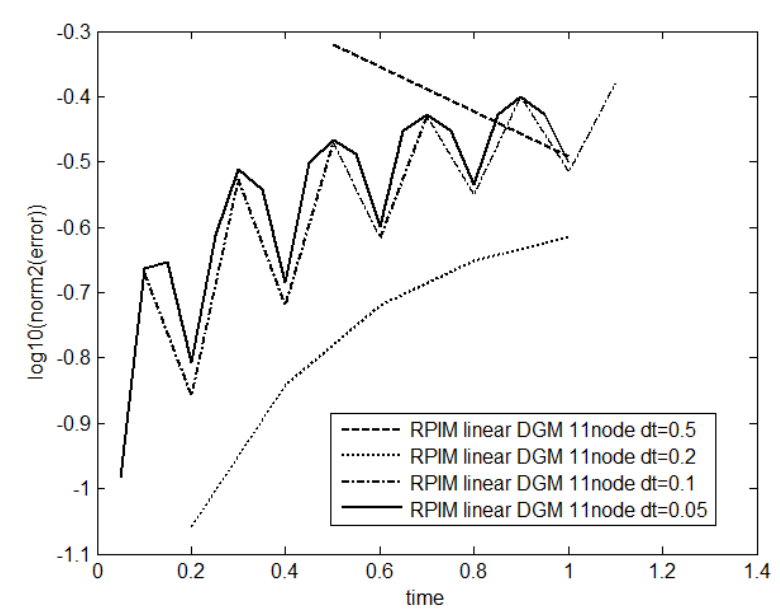

Gambar 5. Time history $\log _{10} \|$ error $\|_{2}$ untuk 11 node, dengan variasi time increment $(\Delta t)$, dengan RPIM linear-DGM.

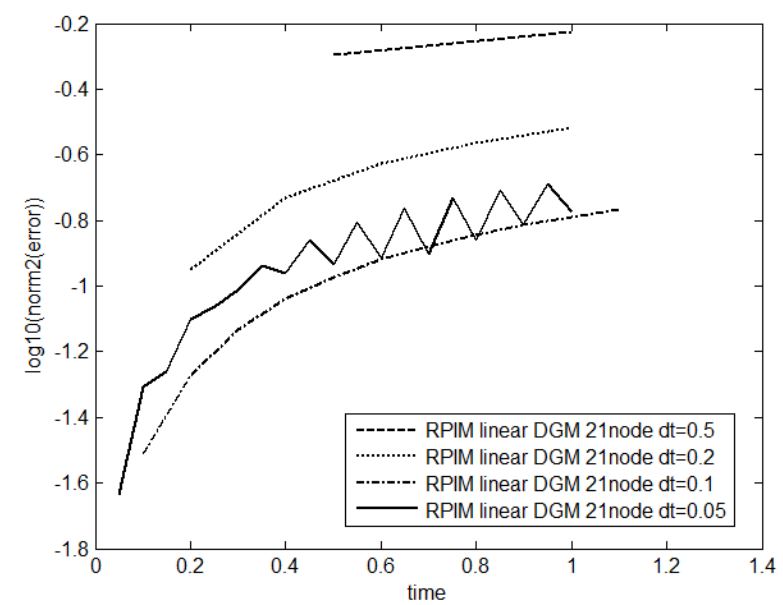

Gambar 6. Time history $\log _{10} \|$ error $\|_{2}$ untuk 21 node, dengan variasi time increment $(\Delta t)$, dengan RPIM linear -DGM.

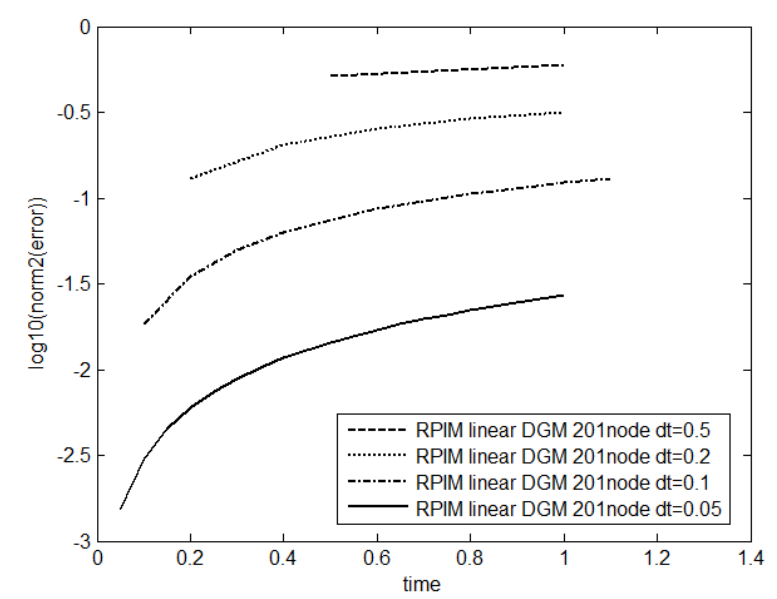

Gambar 7. Time history $\log _{10} \|$ error $\|_{2}$ untuk 201 node, dengan variasi time increment $(\Delta t)$, dengan RPIM linear-DGM.

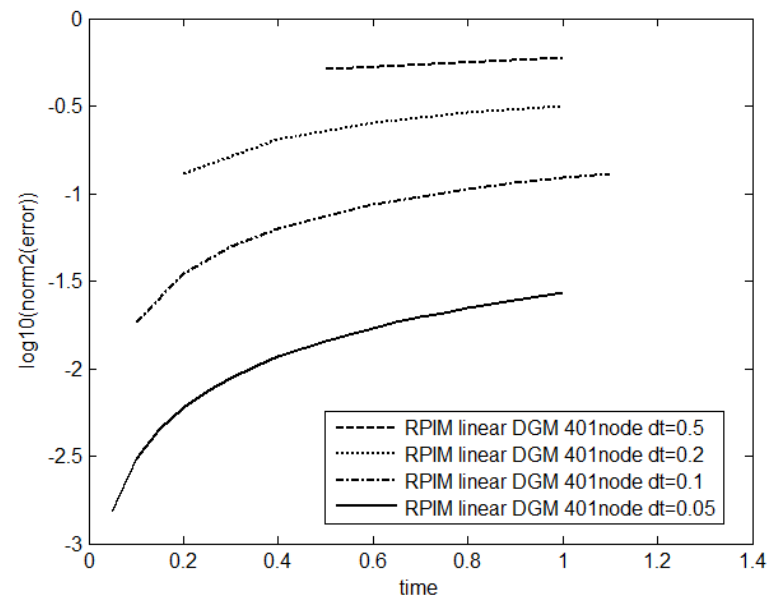

Gambar 8. Time history $\log _{10} \|$ error $\|_{2}$ untuk 401 node, dengan variasi time increment $(\Delta t)$, dengan RPIM linear-DGM.

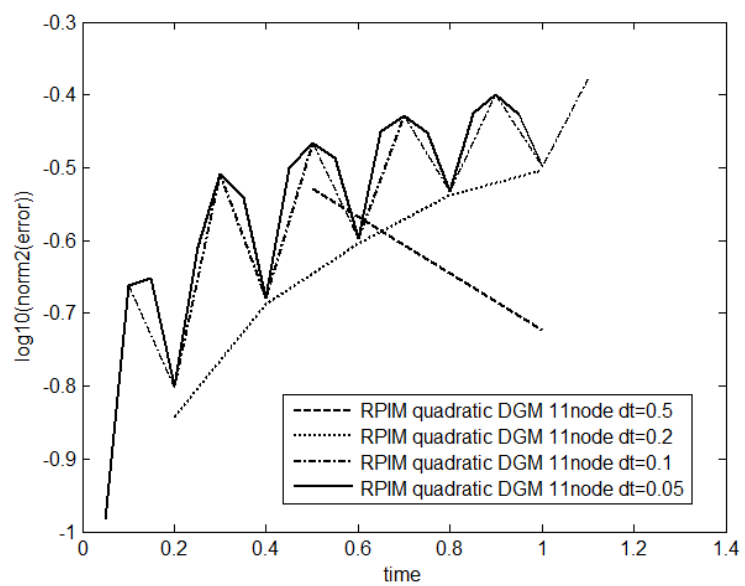

Gambar 9. Time history $\log _{10} \|$ error $\|_{2}$ untuk 11 node, dengan variasi time increment $(\Delta t)$, dengan RPIM quadratic-DGM

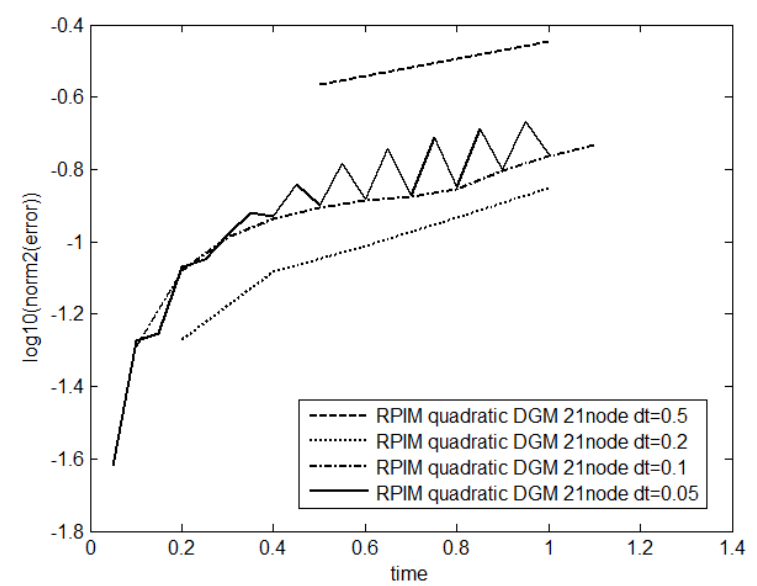

Gambar 10. Time history $\log _{10} \|$ error $\|_{2}$ untuk 21 node, dengan variasi time increment $(\Delta t)$, dengan RPIM quadratic-DGM 


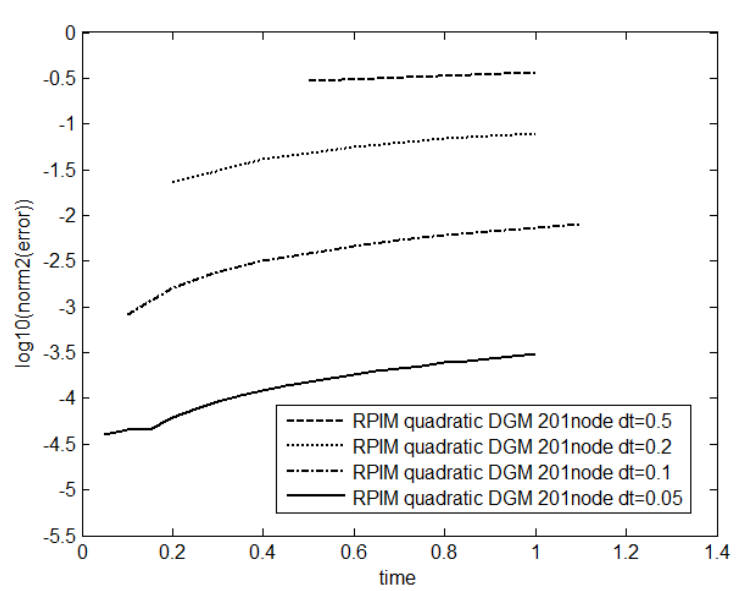

Gambar 11. Time history $\log _{10} \|$ error $\|_{2}$ untuk 201 node, dengan variasi time increment $(\Delta t)$, dengan RPIM quadratic-DGM

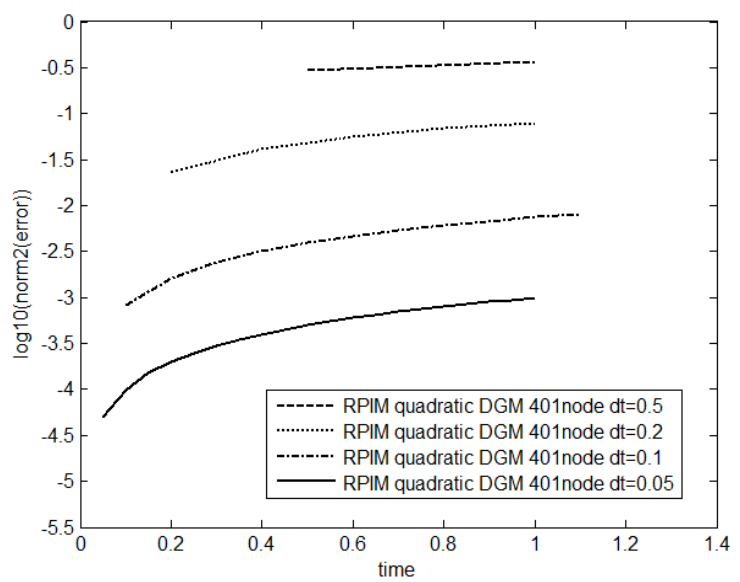

Gambar 12. Time history $\log _{10} \|$ error $\|_{2}$ untuk 401 node, dengan variasi time increment $(\Delta t)$, dengan RPIM quadratic-DGM

Pada RPIM quadratic-DGM, nilai time history error ditampilkan pada Gambar 9, 10, 11 dan 12 untuk beragam jumlah node dan time increment. Seiring dengan waktu, nilai error mengalami peningkatan. Untuk jumlah node semakin banyak dan semakin kecil time increment maka error yang dihasilkan semakin kecil, kecuali pada jumlah node 11 dan 21. Osilasi time history error terjadi juga pada jumlah node 11 dan 21 . Nilai max $\log _{10} \|$ error $\|_{2}$ untuk RPIM quadratic-DGM ditampilkan pada Tabel 1. Untuk suatu jumlah node dan time increment yang digunakan, RPIM quadratic-DGM menghasilkan nilai yang lebih akurat dibandingkan dengan RPIM linearDGM.

Pada Tabel 1, tampak peningkatan jumlah node dari 201 ke 401 peningkatan akurasi atau penurunan nilai error tidak signifikan. Pada RPIM quadraticDGM dengan time increment $\Delta t=0.05$ jumlah peningkatan node malah menurunkan akurasi. Pada Gambar 13 dan 14, nampak bahwa laju konvergensi untuk quadratic DGM lebih tinggi dibandingkan dengan linear DGM.
Tabel 1. Nilai $\max \log _{10}\left\|u_{\text {exact }}-u_{\text {RPIM-DGM }}\right\|_{2}$ dengan RPIM linear-DGM dan RPIM quadratic-

\begin{tabular}{|c|c|c|c|}
\hline $\begin{array}{c}\text { No. } \\
\text { nodes }\end{array}$ & $\Delta t$ & $\begin{array}{c}\text { Max } \\
\log _{10} \| \text { error } \|_{2} \\
\text { (linear } \\
\text { element) }\end{array}$ & $\begin{array}{c}\text { Max } \\
\log _{10} \| \text { error } \|_{2} \\
\text { (quadratic } \\
\text { element) }\end{array}$ \\
\hline 11 & 0.5 & -0.3213 & -0.5293 \\
\hline 11 & 0.2 & -0.6147 & -0.5028 \\
\hline 11 & 0.1 & -0.3793 & -0.3782 \\
\hline 11 & 0.05 & -0.3996 & -0.3995 \\
\hline 21 & 0.5 & -0.2255 & -0.4467 \\
\hline 21 & 0.2 & -0.5187 & -0.8524 \\
\hline 21 & 0.1 & -0.7662 & -0.7309 \\
\hline 21 & 0.05 & -0.6878 & -0.6670 \\
\hline 201 & 0.5 & -0.2239 & -0.4318 \\
\hline 201 & 0.2 & -0.4965 & -1.1008 \\
\hline 201 & 0.1 & -0.8844 & -2.0913 \\
\hline 201 & 0.05 & -1.5682 & -3.5165 \\
\hline 401 & 0.5 & -0.2237 & -0.4318 \\
\hline 401 & 0.2 & -0.4966 & -1.1014 \\
\hline 401 & 0.1 & -0.8841 & -2.0880 \\
\hline 401 & 0.05 & -1.5673 & -3.0027 \\
\hline
\end{tabular}

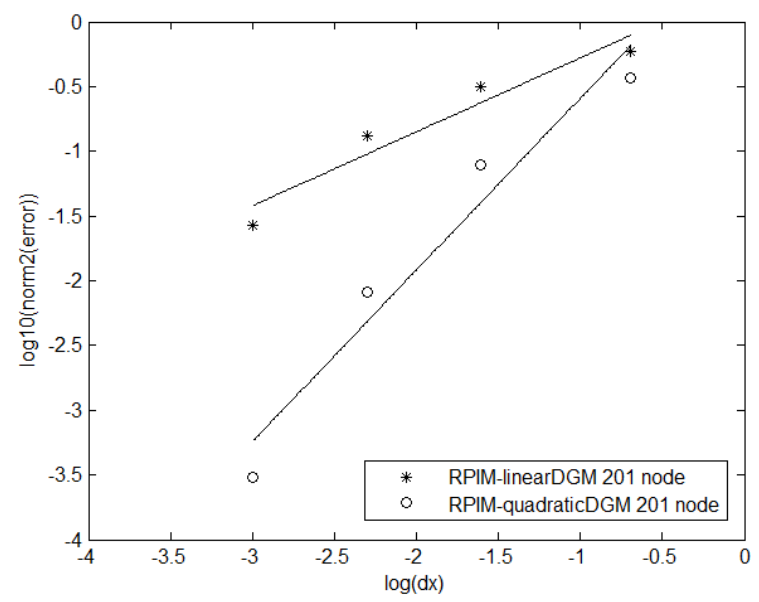

Gambar 13. Laju konvergensi untuk RPIM-DGM untuk 201 node

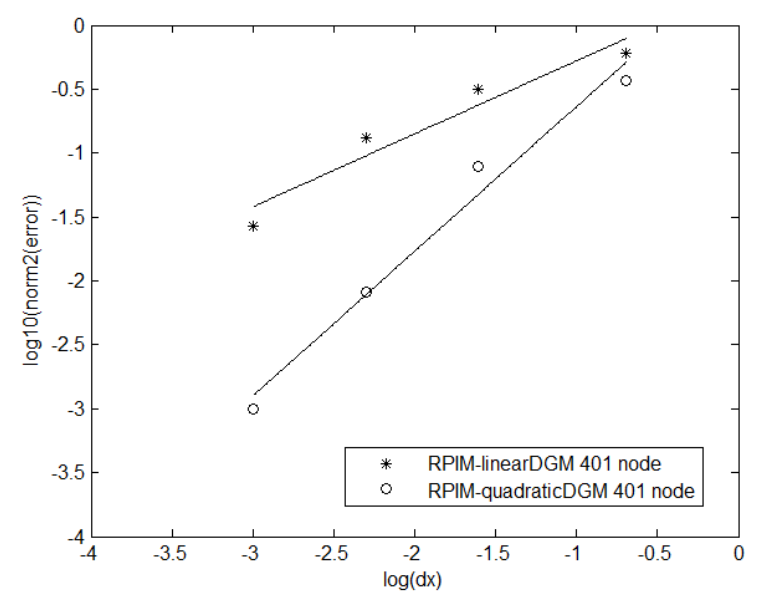

Gambar 14. Laju konvergensi untuk RPIM-DGM untuk 401 node 
Teknik, 37 (2), 2016, 71

Keunggulan dari metode ini adalah integrasi waktu yang dilakukan bersifat implisit sehingga tidak tergantung dari time increment $\Delta t$ yang dipilih dan simulasi tetap berjalan stabil. Kelemahan metode ini adalah degree of freedom (dof) dari simulasi naik menjadi dua kali lipat, akibat dari integrasi waktu dengan DGM. Perhatikan Persamaan 31 dan Persamaan 38 yang memiliki unknown yang lebih banyak. Misalnya untuk integrasi DGM dengan linear elemen memiliki unknown $\mathbf{u}_{k}^{+}$dan $\mathbf{u}_{k+1}^{-}$. Untuk integrasi waktu dengan quadratic elemen memiliki unknown $\mathbf{u}_{k}^{+}, \mathbf{u}_{k+\frac{1}{2}}$ dan $\mathbf{u}_{k+1}^{-}$. Hal ini akan mengakibatkan beban komputasi yang lebih tinggi dari integrasi waktu yang umumnya digunakan.

\section{Kesimpulan}

Dari hasil simulasi menunjukkan metode numerik RPIM-DGM dapat digunakan untuk menyelesaikan persamaan advection. Secara umum semakin banyak node yang digunakan dan semakin kecil time increment yang dipakai maka semakin meningkatkan akurasi RPIM-DGM. Untuk suatu jumlah node dan suatu time increment, quadratic DGM memiliki akurasi yang lebih baik dibandingkan dengan linear DGM.

\section{Daftar Pustaka}

Baptisa, J. (2011). Space-Time Finite Elements Methods in Elastodynamics. Master Thesis. McGill University Canada

Belytschko, T., Liu, Y.Y., \& Gu, L. (1994). ElementFree Galerkin Method. Int. J. Num. Meth. Engng. 37: 229-256

Dolbow J, Belytschko T. 1998. An introduction to programming to meshless element-free Galerkin method. Arch. Comp. Mech. Eng. 5: 207-241

Hesthaven J.S., \& Warburton T. (2008). Nodal Discontinuous Galerkin Method. Springer

Li, B.Q. (2006). Discontinuous Finite Element for Fluid Dynamics and Heat Transfer. Springer

Liu, G.R. (2003). Mesh free method, moving beyond the finite element method. CRC Press

Liu WK, Jun S, Li S, Adee J, Belytschko T. (1995). Reproducing kernel particle method for structural dynamics. Int. J. Numer. Meth. Engng. 38: 1655-1679

Monaghan, J.J. (1992). Smothed Particle Hydrodynamics. Annual Review Astronomy and Astrophysics 30: 543-74

Sarra, S.A., Kansa E.J. (2010). Multiquadratic Radial Basis Function Approximation Method for Numerical Solution of Partial Differential Equations. Tech Science Press

Zienkiewicz, O.C., Morgan, K. (1982). Finite Element and Approximation. John Wiley \& Sons. 